\title{
Parentally reported barriers to seeking help and advice for child sleep from
} healthcare professionals

\section{Georgia Cook, Jane V. Appleton \& Luci Wiggs}

\begin{abstract}
Background: Healthcare professionals (HCPs), largely doctors, paediatricians, health visitors, midwives, and practice nurses, are in a good position to provide information, help, advice, or guidance to parents for child sleep. However, evidence suggests that there is a gap between the number of parents who desire assistance from HCPs and those that make use of these sources, yet very little is known about the reason for this apparent disparity. The aim of this study was to understand the barriers reported by parents to consulting HCPs about child sleep.

Method: In this study, 266 U.K.-based parents of children aged 6-36 months old completed an online questionnaire (between October 2015 and October 2016) about their help-seeking behaviours in relation to child sleep. This included reporting perceived barriers to consulting HCPs for child sleep information and advice about problems.
\end{abstract}

Results: Thematic analysis highlighted five themes, which parents reported acted as barriers to them consulting HCPs. Specifically, parents perceived HCPs to have a lack of knowledge or training around the topic of child sleep and that advice would be limited in terms of breadth of information or management options that would be offered. Parents were also concerned about wasting their own or HCPs' time, perceived there was a lack of continuity in the information they received, and held concerns about possible negative consequences for their family if they shared details about any child sleep difficulties.

Conclusions: Possible practical approaches to address the barriers reported by parents are highlighted. This includes improving training around the topic of child sleep for HCPs and adapting the content or manner in which the topic of child sleep and any associated issues are addressed with parents.

Keywords advice, child sleep, health professionals, help-seeking, parents, sleep problems

\section{Key Messages}

- It is essential that parents' opinions and experiences of consulting healthcare professionals for advice and help about child sleep are understood in order to ensure services best meet parents' needs.

- There are specific barriers that parents report inhibit their use of healthcare professionals for information and advice around child sleep.

- Parental barriers included parents' perceptions of service quality and their expectations of what they would be offered that highlights a misalignment between what parents wanted and what they felt they received.

- A number of approaches could address the barriers reported by parents including improving the training of healthcare professionals around child sleep and adapting the content and/or delivery method of advice. 


\section{Introduction}

Child sleep is a common childhood concern for parents across cultures (Porter \& Ispa, 2013; Sadeh, Tikotzky, \& Scher, 2010; Trajanovska, Manias, Cranswick, \& Johnston, 2010; Mindell, Moline, Zendell, Brown, \& Fry, 1994). Child sleep problems are common, occurring in anywhere up to around $30 \%$ of infants and toddlers (Armstrong, Quinn, \& Dadds, 1994; Byars, Yolton, Rausch, Lanphear, \& Beebe, 2012; Mindell, Meltzer, Carskadon, \& Chervin, 2009). Child sleep problems can have a range of adverse outcomes on children's behaviour and emotional regulation (Scher, Hall, Zaidman-Zait, \& Weinberg, 2010; Sivertsen et al., 2015; Touchette et al., 2007) and cognitive development (Bernier, Carlson, Bordeleau, \& Carrier, 2010; Scher, 2005; Touchette et al., 2007).

Poor child sleep has also been linked to negative outcomes for parents and the wider family unit. Poor child sleep has been repeatedly linked with parental (predominantly maternal) mental health problems (Bayer, Hiscock, Hampton, \& Wake, 2007; Thorne \& Skuladottir, 2005; Lam, Hiscock, \& Wake, 2003; Hiscock \& Wake, 2002; Armstrong, Van Haeringen, Dadds, \& Cash, 1998) and poorer physical and mental health in both mothers and fathers (Martin, Hiscock, Hardy, Davey, \& Wake, 2007). These findings emphasize the need for any child sleep difficulties to be addressed where possible.

There are a range of sources available to parents for information, advice, and help for child sleep. These commonly include healthcare professionals (HCPs), such as doctors, paediatricians, health visitors (HV), midwives, and practice nurses amongst others, as well as a range of informal sources such as friends, family, other parents, the Internet, parenting groups, and books (Tsai, Hu, Lee, \& Wu, 2014; Henderson, Motoi, \& Blampied, 2013; Stremler et al., 2013; Porter \& Ispa, 2013 ; Brady \& Guerin, 2010; France, Blampied, \& Henderson, 2003). There are also many reasons why parents may seek help. For example, this may range from parents seeking general information about a topic to seeking treatment for a specific aspect of their child's sleep behaviour. However, not all parents seek guidance from HCPs, even if they perceive their child to suffer from a sleep problem (Blunden, Thompson, \& Dawson, 2011; Morrell, 1999).

In the U.K. healthcare system, HCPs, particularly HVs, are in a good position to provide information, advice, and help for sleep in the child's early life due to their close work with children and families through U.K. country-specific child health programme contacts (Appleton \& Whittaker, 2019; Department for Health, 2009; DHSSPS, 2010; The Scottish Government, 2017; Welsh Government, 2016). These contacts provide an opportunity for parents to share their concerns about their child, as well as for HCPs to identify families who may require additional support around a range of issues that may include sleep (Hanafin, 2017; Local Government Association, 2017). Yet research suggests that parents do not necessarily make use of such professional sources and that parents' use of HCPs may vary across countries. Research from the United Kingdom suggested that a smaller proportion of parents actually sought help or advice from HCPs in comparison with those that reported desiring support (Morrell, 1999). In Taiwan, Canada, and the United States, mothers have reported to prefer more informal types of sources (e.g., family members, other parents, work colleagues, Internet sites, books or magazines, and local support groups) over professional sources (Johnson, 1991; Stremler et al., 
2013; Tsai et al., 2014). In New Zealand and Australia, the reverse has been found with parents preferring to make use of HCPs over informal sources (Henderson et al., 2013; Trajanovska et al., 2010). Little is known about what factors may inhibit (or promote) consultation with HCPs.

There has been an, albeit limited, exploration into specific barriers that may inhibit parental help seeking related to child sleep. Specific maternal characteristics of being over the age of 25 and having a higher socioeconomic status (SES) have been highlighted as factors, which made mothers significantly more likely to seek help (Henderson et al., 2013). In addition, the alignment between parental beliefs or parenting style and the information offered by sources is likely to be a key factor determining parental use of them. For example, a study of first-time mothers of young infants in Taiwan demonstrated that advice from informal sources was more negatively viewed if it was not in keeping with the preferred maternal parenting style or beliefs (Tsai et al., 2014).

The current study sought to explore parentally reported barriers to help seeking from HCPs in the United Kingdom. To effectively meet the needs of parents of young children, it is essential to understand any barriers experienced by parents, which may impact upon their desire and/or ability to obtain appropriate information or help. Understanding parents' help-seeking behaviours has implications for the training and practice of HCPs who may discuss the topic of sleep with parents. Ensuring that any possible barriers to parents' consultation with HCPs are addressed will contribute to ensuring that HCPs best meet parents' needs and would hopefully help to maximize the number of families who can access and benefit from appropriate HCP support.

\section{Method}

\section{Participants and recruitment}

Parents of 6- to 36-month-old children, living in the United Kingdom, were recruited through several predominantly online sources such as Facebook and Twitter, online parenting groups, and via the University's Babylab database (a database of parents in the local area who have taken part in, or expressed an interest in, participating in child research at the University).

After exclusions due to child age (outside of 6-36 months old), parental location (outside of the United Kingdom), and questionnaires not completed in full, 266 questionnaires were included in the analysis. Of these, $259(97 \%)$ were completed by mothers. Parents were aged $21-45$ years, based on age data provided by 261 parents $(M=33.49$ years, $S D=4.71)$.

The ethnicity of the overall sample was predominantly White British (87.2\%). The sample was generally well educated, with over three quarters $(78.9 \%)$ holding a bachelors university level degree or above. Just over half of the sample held managerial, director, senior official, professional, or technical occupations, suggesting that the sample was of high SES. Many counties across the United Kingdom were represented $(n=48)$; although, a large proportion of responses $(38.4 \%)$ came from four counties in the South of England. 
Of the 266 children about whom parents completed the questionnaire, 139 (52\%) were boys and 127 (48\%) were girls. The age range of children was 6-36 months (M $=19.41$ months, $\mathrm{SD}=9.26)$.

\section{Measures}

Given that the topic of parental help seeking in relation to child sleep has received little previous empirical exploration, there were no existing measures to assess the desired topics. Therefore, a questionnaire was developed exclusively for use in the current study. Questionnaire items were initially produced by the researcher based on aspects of parental help-seeking behaviours that were of interest in the current study, from discussion with experts in child sleep and reviewing the small amount of literature in this area. Items were then repeatedly reviewed and refined, in collaboration with clinical and research specialists in the field of sleep, and with children and families, as well as two families with children in the target age range.

The final questionnaire assessed a range of aspects including parents' perception of their child's sleep, use of sources, experiences of interventions, reasons for not having sought help for their child's sleep, help-seeking behaviours, and barriers to the use of specific types of sources. The final questionnaire comprised 24 items. Some questions were nested and only shown to participants based on responses to other questions, so the exact number of questions seen by each participant varied depending upon individual responses. All parents were presented with a minimum of 13 items. The current results focus solely on parents' responses to one open-ended question, which asked parents to report if there were any barriers or issues that would limit their use of HCPs: "If you have any reservations about using any of these options [list of various HCPs] for advice about your child's sleep, now or in the future, what are they?" Parents recorded their answers in an open-ended text box. Parents were not required to provide an answer.

\section{Procedure}

Ethical approval was obtained through the University's Research Ethics Committee. Data were collected on October 29, 2015, to October 31, 2016. When participants accessed the online questionnaire, they were presented with the participant information sheet and provided informed consent (by ticking a box online) before accessing the questionnaire. Participants could leave the questionnaire at any point. Incomplete questionnaires stayed live for a week, but once this period had passed, the questionnaire was closed and not included in the analysis. Only fully completed and submitted responses were analysed. All parents who completed the questionnaire and left a valid email address were entered into a prize draw to win a $£ 50$ Amazon voucher. During the period in which data were collected, adverts and links to the questionnaire were regularly refreshed and reposted both on the research project social media pages and parenting websites.

\section{Analysis procedure}

Qualitative data were thematically analysed following the standardized guidelines developed by Braun and Clarke (2006). This process involves six distinct stages: familiarization with the data; generating initial codes; searching for themes; reviewing themes; defining and naming themes; and finally producing the written analysis. Thematic analysis was deemed the most suitable analysis method, as it is a theoretically flexible approach, which is not bound to any specific methodology and 
can be used as a standalone method for analysing data. An inductive thematic analysis approach was employed, whereby themes were derived from the data in a "bottom-up" approach. Thus, participants' own words were the starting point from which more general themes were developed. To ensure a rigorous approach to data analysis, after the researcher had conducted the initial steps of thematic analysis on the data, a proportion of the data ( $11 \%$ of the overall data set) were reviewed by (LW and JA) and an additional qualitative researcher who was not involved in the project $(\mathrm{KH})$.

The researchers and supervisors separately discussed and refined the codes and themes generated in the study to reach agreement that the final themes reliably and accurately embodied the detail present in the participants' original data. This approach sought to ensure the quality and credibility of the analysis (Barbour, 2001; Nowell, Norris, White, \& Moules, 2017). Each theme is presented with a description of how this theme was conceptualized alongside supporting quotes from participants. The presence of each theme across individual participants' qualitative data was identified so that a frequency count for each theme could be generated. Due to the sample size, this provided an indication of the strength of the presence of each different theme across the sample and is included alongside each theme. In a small number of places where clear typographic or grammatical errors were made by parents, these were corrected for clear illustrative supporting quotations.

\section{Results}

A large proportion of parents of 6 - to 36 -month olds $(n=182,68 \%)$ provided a text response to the questionnaire item asking them to report any reservations for using HCPs for information and help for child sleep from which five themes and two subthemes related to perceived barriers were identified.

Lack of knowledge or training (reported by 62 parents)

There was a belief amongst 62 parents that HCPs lacked knowledge about child sleep, such as this mother who when asked about her use of HCPs in relation to child sleep reported "my previous health visitor was not someone I respected as she appeared uneducated and inexperienced" (Mum, 31, of girl 28 months).

There was also a prevailing belief amongst some parents that HCPs' knowledge and skills around child sleep were negatively affected by limited or insufficient training on this topic:

Recommend CC [Controlled Crying], $\mathrm{ClO}$ [Cry it out] etc. no real help. Many don't have children and seem to have minimal training on sleep so I am not happy to turn to them. (Mum, 28, of girl 7 months)

Clearly, if U.K. HCPs lack adequate training and knowledge about child sleep and any associated issues, including management options and their supporting evidence, it is unlikely that they would be in a position to provide adequate guidance, provide assessment, or deliver appropriate recommendations to parents. This may account for the reservations to using HCPs reported by some parents in the current study. 
Professionals lack of flexibility (reported by 54 parents)

Many parents perceived that the information, advice, or treatment options offered by HCPs, particularly from HVs, could only be based upon officially sanctioned recommendations and therefore were generic and lacked flexibility. One father felt that HCPs only offered a "mainstream approach and generally just ticking boxes" (Dad, 40, of boy 33 months).

The perception that HCPs lacked flexibility negatively influenced parents' views of their value and parents' likelihood to use them in the future:

Have found them narrow-minded, judgemental and critical of anything other than cry-it-out, so reluctant to ask them for any advice on anything ever again. (Mum, 41, of boy 14 months)

For many parents, a primary concern regarding professional flexibility was that HCPs' advice would not align with their desired approaches to parenting:

Standard answers which leave you feeling like you are doing something wrong. Crying it out is NOT the way to fix anything. When I explained my reservations to the HV [health visitor] she told me that I would have to do it anyway. Horrifying that some mothers may then do this as a result of the appalling information issued. (Mum, 31, of girl 9 months)

Many parents in the current study appeared to desire gentle or attachment parenting-based methods, not behaviourally based interventions, but it was the latter that most parents had been, or perceived they would be, offered by HCPs. For example, one mother felt that HCPs offered "out of date ideas sometimes. Need reeducating on gentler methods? Science behind it" (Mum, 31, of boy 26 months). However, what is not clear from the current study is which aspects of behaviourally based methods parents were specifically averse to.

Concerns about wasting time (reported by 34 parents)

Parents had reservations about wasting time in two distinct ways. First, many parents were concerned that their visits would be viewed by HCPs as a waste of their time:

I wouldn't want to feel like I was wasting the time of a health professional, especially the doctor. I don't believe midwives are trained in child sleep and I think more should be trained in safe co-sleeping to be able to help desperate mothers in the early days. Ditto health visitors. Mine is very good but I am not clear on what her role is supposed to be and whether I am 'allowed' to contact her. (Mum, 37, of girl 16 months)

Second, there were also parents who made the potentially erroneous assumption that any visit to HCPs for their child's sleep would be a waste of their own time. These parents thought a visit to HCPs would not be worthwhile, as they did not believe that they would be offered beneficial information or advice. For example, one mother reported "I have reservations about using HV's [health visitors] just through past experience of useless advice" (Mum, 40, of girl 27 months). 
These parental perceptions need to be understood and addressed, as neither are conducive to productive relationships and currently parents' concerns appear to be undermining their confidence and future use of HCPs.

Two subthemes further explained why parents might feel that consulting HCPs could be a waste of time: parents)

Dismissive or patronizing attitude towards parents (reported by 38

A further barrier reported by many parents was the perception that HCPs would not be approachable or supportive of concerns around child sleep. One mother reported that "health professionals tend to speak down to me as a mother and brush off my concerns, making me feel bad and stupid" (Mum, 33, of girl 26 months).

Given the emotive nature of child sleep and the impact sleep deprivation can have on parents, it appeared extremely important for parents to feel appropriately supported by those professionals they approached about sleep issues. For example, one mother reported that her reservation for using an HCPs was because her past experience had been that they "don't seem to care. Maybe lack of time or resources but I feel like a pain if I go about this issue [sleep]" (Mum, 28, of girl 36 months). These parental views suggest that the perceived manner of professionals could influence parents' opinions about HCPs and approaching them in the future.

Sleep not seen as an important issue for HCPs (reported by 19 parents) Some parents perceived that HCPs did not regard sleep as an important issue, which resulted in frustration and disenchantment:

Have never found medical professionals helpful for sleep-they don't seem to consider it an issue or haven't been very supportive/given very clear/helpful advice. (Mum, 34, of boy 12 months)

Alternatively, many parents did not feel that child sleep was a concern that they should raise with HCPs. In some cases, parents clearly felt the onus for dealing with child sleep fell to them:

Feel they're too busy, that I should know how to manage my child by now. Also, that every mum goes through sleep problems with their child so I should just deal with it. It's a small issue in comparison to other problems. (Mum, 30, of boy 25 months)

The fact that many parents did not feel that the HCP acknowledged or adequately dealt with their child's sleep or that child sleep was not something that they should raise with HCPs is concerning given the common nature of child sleeplessness problems and the adverse outcomes if left untreated.

Parental concerns about negative consequences for family (reported by 24 parents)

Some parents held concerns that they would be poorly judged if they admitted that they were struggling or needed help for child sleep. For example, one mother reported that "sometimes I feel like I have to show my HV [health visitor] that I'm 
coping and as a result I don't feel I can be honest about what's happening" (Mum, 34 , of girl 10 months).

For some parents, HCPs were seen as being in a position of power (due to dealing directly with families), and there were concerns about possible negative outcomes if parents did not implement what was recommended by the HCP. One mother said that "I don't trust them to be impartial. Would be concerned that if I chose to ignore their advice they wouldn't just leave us to it" (Mum, 34, of girl 24 months). In addition, some parents felt that even raising the issue of child sleep could have negative outcomes for their family and how they were perceived by HCPs:

Feel that you are being judged \& labelled as a "bad parent" and "struggling to cope", \& may go on a list as a concern. (Mum, 28, of boy 29 months)

Given that child sleep patterns and the types of problems parents face around child sleep change over the course of development, it is likely that many parents will require sleep-related advice and support at one time or another. It is therefore important that parents feel confident and comfortable sharing the true nature of their child's sleep and any issues they experience.

Lack of continuity or conflicting information from HCPs (reported by 22 parents) An additional parental reservation was around the perceived lack of continuity between the HCPs they saw and the information they received, which for many parents was confusing and unsettling:

I feel like there is inconsistency between healthcare professionals, I've been given differing advice on the same issue by different HVs [health visitor] and GPs [General Practitioner or Family Doctor]. (Mum, 38, of boy 22 months)

Obtaining different, or what parents perceived to be incorrect, advice across sources was frustrating and confusing and resulted in parents losing confidence in the quality of HCPs advice:

Never again - I have received nothing but outdated and conflicting advice, given without me asking and with plenty of snap judgements. (Mum, 34, of boy 22 months)

To instil confidence in parents, it appears crucial to ensure sleep information and advice delivered to parents is consistent and nonconflicting. This may be straightforward for some aspects of child sleep such as ensuring that all HCPs have up to date knowledge and training around developmental aspects of child sleep.

However, there is an apparent tension for other aspects such as treatment methods, as it is challenging to ensure consistency and continuity while also acknowledging that parents desire flexibility and nongeneric recommendations.

\section{Discussion}

Parents reported a number of barriers to consulting HCPs for information, help, or treatments for their child's sleep. These concerns focused around parental perceptions that HCPs had limited knowledge about the topic and lacked flexibility in the range of options that they would offer parents to manage or improve child sleep. 
Many parents felt that seeking help for child sleep would be a waste of time and that, if they raised concerns about child sleep, these would not be taken seriously by HCPs. Parents felt that information from HCPs often lacked continuity, and in some cases, parents had worries about negative outcomes if they admitted needing help or support for child sleep.

The parental perception that HCPs lack appropriate training and knowledge around child sleep appears to be supported by empirical evidence. Nearly half of HVs reported that they had received little or no professional training around children's sleep problems (Netmums \& Institute of Health Visiting survey, 2012). Evidence from outside of the United Kingdom has also identified similar inadequacies in HCP training and confidence about child sleep (Faruqui, Khubchandani, Price, Bolyard, \& Reddy, 2011; Mindell et al., 2013). A practical approach to addressing this barrier could be to undertake additional research to assess and, if necessary, address through training and development, any gaps in HCPs' knowledge, and training regarding child sleep. For example, it is clear that HVs in England are expected to provide advice and guidance to parents on child sleep issues as part of the Healthy Child Programme (Department for Health, 2009). Identifying and addressing any gaps in their knowledge and training/professional development could help to ensure that they are well prepared and able to deliver universal, appropriate advice, and support to parents. Additionally, parents could be supported by specialized support, if necessary, such as through universal plus or "targeted indicated" services (Asmussen \& Brims, 2018; Cowley et al., 2013).

Another barrier that the current study has highlighted is an apparent tension between the type of help and treatment methods that parents desired and what they anticipated they would be offered by HCPs. This resulted in parents perceiving that many HCPs lacked flexibility in the scope of information and advice they could, or would, offer. Therefore, similar to previous studies, results of the current study suggest that HCPs face challenges in delivering evidence-based information to parents in everyday practice (van Bekkum \& Hilton, 2013).

Although mandated to provide evidence-based advice, this study suggests that it is crucial for HCPs to have the knowledge and practical flexibility to provide parents with information of what is known (or not) about a range of different management and/or treatment options. Adopting this sort of approach, which it is likely that some services and individuals may already implement, could help parents to feel that their parenting beliefs are not dismissed. However, it is not clear if this approach would be feasible for HCPs, even if they desired to do so, given the reduction in staff numbers, funding cuts, and increasing workloads (BMA, 2018; IHV, 2016).

Given that child sleep is clearly an important issue for families (Porter \& Ispa, 2013; Trajanovska et al., 2010), the belief that HCPs would not view the matter similarly resulted in feelings of frustration and disenchantment with HCPs and the system more generally. In the current study, this was reflected through parental concerns about wasting HCPs' time and the manner in which HCPs would deal with child sleep issues they raised. Therefore, the importance of HCPs having interpersonal skills that foster reciprocal trust and suggest empathy is clearly emphasized in the current study. 
Although it is likely that many HCPs adopt a supportive and understanding approach with parents, the current study suggests that this is not always perceived to be the case and that HCPs' training and practice could helpfully reiterate the importance of positive reciprocal relationships and specifically seek to develop skills (such as empathy and compassion) beneficial to contacts with families. Parents of young children are commonly fatigued or sleep deprived (Insana \& Montgomery-Downs, 2013), and this can have a profound effect on aspects of functioning, including anxiety, mood, and stress (Babson, Trainor, Feldner, \& Blumenthal, 2010; Meltzer \& Mindell, 2007), which may make them especially sensitive to any perceived negativity in their interactions with others. However, solutions to these problems may be challenging to achieve, as they would likely require additional contact time, which may not be feasible given the financial and workload constraints within which many HCPs operate.

Further, some parents held concerns about possible repercussions of admitting to HCPs that there was a problem (e.g., that their child's sleep problem would be construed as reflecting a deficiency in their parenting ability). Perhaps this barrier could be simply addressed by making HCPs aware of this parental reservation. In doing so, HCPs could adapt their practice and ensure that early HCP interactions with parents make it clear that child sleep problems are commonly experienced by many families for many different reasons, however, if they arise, can often be fairly easily addressed through behaviourally based interventions, which have the strongest evidence base and are commonly the preferred first-line treatment for health services (Mindell, Kuhn, Lewin, Meltzer, \& Sadeh, 2006; Wilson et al., 2010). It could also help to allay parental concerns about using behaviourally based methods to ensure that it is clearly communicated that these vary in nature and are not purely, as many parents appear to perceive, based on "cry it out" type extinction techniques.

Finally, parents also held concerns regarding the lack of consistency of information they received, which for many was seen as confusing and unsettling. As previously highlighted, improving HCPs' knowledge and training around child sleep may improve the consistency of information given to parents. However, there is clearly also a practical challenge for HCPs to meet parents' needs within the constraints of the healthcare system (BMA, 2018; IHV, 2016).

Parents strongly highlighted concerns about both the content and delivery method of advice and support for child sleep. However, it is not clear if changes to one or both of these aspects are needed to meet parents' needs. Perhaps, it would be sufficient to adapt what information is provided to parents. Alternatively, perhaps adapting how content is framed, explained, and communicated without necessarily altering the underlying advice could effectively address the parental concerns highlighted.

Due to the lack of a standardized questionnaire to assess parental help-seeking behaviours, a measure was devised to assess this aspect in the current study, and it is possible that this did not fully capture or reflect the subtleties of parents' barriers to using HCPs for child sleep. There is also the potential for sample bias as the current sample comprised mainly mothers who were predominantly White, and of above average education, and SES. In addition, although the study was open to all U.K. parents, some geographical areas were underrepresented. For example, rural 
Scotland and Wales were represented by only a handful of parents; results may not therefore be considered representative of the whole of the United Kingdom. Parents who had had a negative experience of seeking help regarding child sleep with an HCP may also have been more likely to respond.

Future studies could seek to extend this preliminary exploratory study by examining parentally reported barriers to using HCPs for child sleep in a larger, more demographically and geographically representative sample, which may be important to consider, as local service provision is likely to vary across the country and may influence help-seeking behaviours. Better understanding of parental barriers to using HCPs for information or help for child sleep could also be achieved by conducting interviews with parents, so that issues they raise could be probed further.

Additionally, future studies could also helpfully explore HCPs' perceptions of the provisions available to support parents. A clearer, integrated understanding of both parents' and HCPs' perspectives is required in order to decide upon appropriate and practical suggestions for possible solutions.

Findings clearly suggest that many parents believe that there are barriers to their use of HCPs for support with their child's sleep. Some possible approaches to counteract or minimize the impact of these factors have been suggested. However, additional research is required to ensure that the full range of barriers experienced by parents is understood and to identify the most successful approaches to reducing these.

\section{Acknowledgements}

This research was conducted as part of the first author's PhD research programme at Oxford Brookes University and was funded by a Nigel Groome scholarship. The authors would like to thank all participating families for their involvement. Thanks also to Dr Kimberley Harcourt who contributed to the thematic analysis process.

\section{References}

Appleton, J. V., \& Whittaker, K. (2019). Assessing the health needs of children. In J. Howarth, \& D. Platt (Eds.), The Child's World (3rd edition) (pp. 319-351). London: Jessica Kingsley Publishers.

Armstrong, K. L., Quinn, R. A., \& Dadds, M. R. (1994). The sleep patterns of normal children. The Medical Journal of Australia, 161(3), 202-206.

https://doi.org/10.5694/j.1326-5377.1994.tb127383.x

Armstrong, K. L., Van Haeringen, A. R., Dadds, M. R., \& Cash, R. (1998). Sleep deprivation or postnatal depression in later infancy: Separating the chicken from the egg. Journal of Paediatrics and Child Health, 34, 260-262.

https://doi.org/10.1046/j.1440-1754.1998. 00213.x

Asmussen, K., \& Brims, L. (2018). What works to enhance the effectiveness of the healthy child programme: An evidence update. London: Early Intervention Foundation.

Babson, K. A., Trainor, C. D., Feldner, M. T., \& Blumenthal, H. (2010). A test of the effects of acute sleep deprivation on general and specific selfreported anxiety and 
depressive symptoms: An experimental extension. Journal of Behavior Therapy and Experimental Psychiatry, 41(3), 297-303. https://doi.org/10.1016/j.jbtep.2010.02.008

Barbour, R. S. (2001). Checklists for improving rigour in qualitative research: A case of the tail wagging the dog? BMJ, 322(7294), 1115-1117.

https://doi.org/10.1136/bmj.322.7294.1115

Bayer, J. K., Hiscock, H., Hampton, A., \& Wake, M. (2007). Sleep problems in young infants and maternal mental and physical health. Journal of Pediatrics and Child Health, 43, 66-73. https://doi.org/10.1111/j. 1440-1754.2007.01005.x

Bernier, A., Carlson, S. M., Bordeleau, S., \& Carrier, J. (2010). Relations between physiological and cognitive regulatory systems: Infant sleep regulation and subsequent executive functioning. Child Development, 81(6), 1739-1752. https://doi.org/10.1111/j.1467-8624.2010. 01507.x

Blunden, S. L., Thompson, K. R., \& Dawson, D. (2011). Behavioural sleep treatments and night time crying in infants: Challenging the status quo. Sleep Medicine Reviews, 15, 327-334. https://doi.org/10.1016/j. smrv.2010.11.002

Brady, E., \& Guerin, S. (2010). "Not the romantic, all happy, coochy coo experience": A qualitative analysis of interactions on an Irish parenting web site. Family Relations, 59, 14-27. https://doi.org/10.1111/j.1741- 3729.2009.00582.x

Braun, V., \& Clarke, V. (2006). Using thematic analysis in psychology. Qualitative Research in Psychology, 3(2), 77-101. https://doi.org/10.1191/ 1478088706qp063oa

British Medical Association (2018). Feeling the squeeze-the local impact of cuts to public health budgets in England. London: BMA.

Byars, K. C., Yolton, K., Rausch, J., Lanphear, B., \& Beebe, D. W. (2012).

Prevalence, patterns, and persistence of sleep problems in the first 3 years of life.

Pediatrics, 129(2), e276-e284. https://doi.org/10. 1542/peds.2011-0372

Cowley, S., Whittaker, K., Grigulis, A., Malone, M., Donetto, S., Wood, H., ... Maben, J. (2013). Why health visiting? A review of the literature about key health visitor interventions, processes and outcomes for children and families. King's College, London: National Nursing Research Unit.

Department of Health (2009). Healthy child programme: Pregnancy and the first five years. London: Department of Health. Retrieved from. https:// assets.publishing.service.gov.uk/government/uploads/system/ uploads/attachment_data/file/167998/Health_Child_Programme.pdf

Department of Health, Social Services and Public Safety (DHSSPS) (2010). Healthy Child, healthy future. A framework for the universal child health promotion programme in Northern Ireland: Pregnancy to 19 years. Belfast: DHSSPSNI. Retrieved from. https://www.health-ni.gov.uk/sites/ default/files/publications/dhssps/healthychildhealthyfuture.pdf 
Faruqui, F., Khubchandani, J., Price, J. H., Bolyard, D., \& Reddy, R. (2011). Sleep disorders in children: A national assessment of primary care paediatrician practices and perceptions. Pediatrics, 128(3), 539-546. https://doi.org/10.1542/peds.20110344

France, K. G., Blampied, N. M., \& Henderson, J. M. T. (2003). Infant sleep disturbance. Current Pediatrics, 13(3), 241-246. https://doi.org/10. 1016/S09575839(03)00004-6

Hanafin, S. (2017). Sleep patterns and problems in infants and young children in Ireland. Child Care, Health and Development, 1-6. https://doi.

org/10.1111/cch.12539

Henderson, J. M. T., Motoi, G., \& Blampied, N. M. (2013). Sleeping through the night: A community survey of parents' opinions about and expectations of infant sleep consolidation. Journal of Pediatrics and Child Health, 49(7), 535-540. https://doi.org/10.1111/jpc.12278

Hiscock, H., \& Wake, M. (2002). Randomised controlled trial of behavioural infant sleep intervention to improve infant sleep and maternal mood. BMJ, 324(7345), 1062-1065. https://doi.org/10.1136/bmj. 324.7345.1062

Insana, S. P., \& Montgomery-Downs, H. E. (2013). Sleep and sleepiness among first-time postpartum parents: A field- and laboratory-based multimethod assessment. Developmental Psychobiology, 55(4), 361-372. https://doi.org/10.1002/dev.21040

Institute of Health Visiting (2016). Public Health spending cuts stop health visitors protecting and supporting mothers and babies. Retrieved from https://ihv.org.uk/news-and-views/press-releases/public-healthspending-cuts-stophealth-visitors-protecting-supporting-mothersbabies/.

Johnson, C. M. (1991). Infant and toddler sleep-A telephone survey of parents in one community. Journal of Developmental and Behavioral Pediatrics, 12(2), 108114. https://doi.org/10.1097/00004703- 199104000-00007 I

Lam, P., Hiscock, H., \& Wake, M. (2003). Outcomes of infant sleep problems: A longitudinal study of sleep, behavior, and maternal well-being. Pediatrics, 111(3), 203-207. https://doi.org/10.1542/peds.111.3.e203

Local Government Association (2017). Improving outcomes for children and families in the early years: A key role for health visiting services. Retrieved from https://www.local.gov.uk/improving-outcomeschildren-and-families-early-years-keyrole-health-visiting-services.

Martin, J., Hiscock, H., Hardy, P., Davey, B., \& Wake, M. (2007). Adverse associations of infant and child sleep problems and parent health: An Australian population study. Pediatrics, 119(5), 947-955. https://doi. org/10.1542/peds.20062569 
Meltzer, L. J., \& Mindell, J. A. (2007). Relationship between child sleep disturbances and maternal sleep, mood, and parenting stress: A pilot study. Journal of Family Psychology, 21(1), 67-73. https://doi.org/10. 1037/0893-3200.21.1.67

Mindell, J. A., Bartle, A., Ahn, Y., M. B., Ramamurthy, M. B., Huong, H. T. D., Kohyama, J., ... Goh, D. Y. T. (2013). Sleep education in pediatric residency programs: A cross-cultural look. BMC Research Notes, 6, 130.

https://doi.org/10.1186/1756-0500-6-130

Mindell, J. A., Kuhn, B., Lewin, D. S., Meltzer, L. J., \& Sadeh, A. (2006). Behavioral treatment of bedtime problems and night wakings in infants and young children.

Sleep, 29(10), 1263-1276. https://doi.org/ 10.1093/sleep/29.10.1263

Mindell, J. A., Meltzer, L. J., Carskadon, M. A., \& Chervin, R. D. (2009).

Developmental aspects of sleep hygiene: Findings from the 2004 National Sleep

Foundation Sleep in America Poll. Sleep Medicine, 10(7), 771-779.

https://doi.org/10.1016/j.sleep.2008.07.016

Mindell, J. A., Moline, M. L., Zendell, S. M., Brown, L. W., \& Fry, J. M. (1994).

Pediatricians and sleep disorders: Training and practice. Pediatrics, 94, 194-200.

Morrell, J. M. B. (1999). The role of maternal cognitions in infant sleep problems as assessed by a new instrument, the maternal cognitions about infant sleep questionnaire. The Journal of Child Psychology and Psychiatry, 40(2), 247-258. https://doi.org/10.1111/1469-7610. 00438

Netmums and Institute of Health Visiting survey (2012) cited in Fisher, M. (2013). Sleep matters for health visitors: evidence and best practice. Nursing in practice health visitor supplement. Retrieved from http://

www.nursinginpractice.com/article/sleep-matters-health-visitorsevidence-and-bestpractice

Nowell, L. S., Norris, J. M., White, D. E., \& Moules, N. J. (2017). Thematic analysis: Striving to meet the trustworthiness criteria. International Journal of Qualitative Methods, 16(1), 1-13.1609406917733847. doi: 10.1177/1609406917733847

Porter, N., \& Ispa, J. M. (2013). Mothers' online message board questions about parenting infants and toddlers. Journal of Advanced Nursing, 69(3), 559-568. https://doi.org/10.1111/j.1365-2648.2012.06030.x

Sadeh, A., Tikotzky, L., \& Scher, A. (2010). Parenting and infant sleep. Sleep Medicine Reviews, 14(2), 89-96. https://doi.org/10.1016/j.smrv.2009. 05.003

Scher, A. (2005). Infant sleep at 10 months of age as a window to cognitive development. Early Human Development, 81(3), 289-292.

https://doi.org/10.1016/j.earlhumdev.2004.07.005

Scher, A., Hall, W. A., Zaidman-Zait, A., \& Weinberg, J. (2010). Sleep quality, cortisol levels, and behavioral regulation in toddlers. Developmental Psychobiology, 52(1), 44-53. https://doi.org/10.1002/dev. 20410 
Sivertsen, B., Harvey, A. G., Reichborn-Kjennerud, T., Torgersen, L., Ystrom, E., \& Hysing, M. (2015). Later emotional and behavioral problems associated with sleep problems in toddlers. JAMA Pediatrics, 169(6), 575-582.

https://doi.org/10.1001/jamapediatrics.2015.0187

Stremler, R., Hodnett, E., Kenton, L., Lee, K., Weiss, S., Weston, J., \& Willan, A. (2013). Effect of behavioural-educational intervention on sleep for primiparous women and their infants in early postpartum: Multisite randomised controlled trial. British Medical Journal, 346, f1164. https://doi.org/10.1136/bmj.f1164

The Scottish Government (2017). GIRFEC (getting it right for every child). Retrieved from www.gov.scot/Topics/People/Young-People/ gettingitright/what-is-girfec

Thorne, M., \& Skuladottir, A. (2005). Evaluating a family-centred intervention for infant sleep problems. Journal of Advanced Nursing, 50(1), 5-11.

https://doi.org/10.1111/j.1365-2648.2004.03343.x

Touchette, E., Petit, D., Seguin, J. R., Boivin, M., Tremblay, R. E., \& Montplaisir, J. Y. (2007). Associations between sleep duration patterns and behavioral/cognitive functioning at school entry. Sleep, 30(9), 1213-1219.

https://doi.org/10.1093/sleep/30.9.1213

Trajanovska, M., Manias, E., Cranswick, N., \& Johnston, L. (2010). Parental management of childhood complaints: Over-the-counter medicine use and adviceseeking behaviours. Journal of Clinical Nursing, 19(13-14), 2065-2075. https://doi.org/10.1111/j.1365- 2702.2009.03092.x

Tsai, S. Y., Hu, W. Y., Lee, Y. L., \& Wu, C. Y. (2014). Infant sleep problems: A qualitative analysis of first-time mothers' coping experience. Midwifery, 30(6), 750755. https://doi.org/10.1016/j.midw.2013.08.005

Van Bekkum, J. E., \& Hilton, S. (2013). The challenges of communicating research evidence in practice: Perspectives from UK health visitors and practice nurses. BMC Nursing, 12(17), 1-9. https://doi.org/10. 1186/1472-6955-12-17

Welsh Government (2016). Healthy child wales programme: Quality assurance framework. Cardiff: Welsh Government. Retrieved from. http:// fis.ceredigion.gov.uk/healthy-child-wales-programmehcwp

Wilson, S. J., Nutt, D. J., Alford, C., Argyropoulos, S. V., Baldwin, D. S., Bateson, A. N., ... Wade, A. G. (2010). British Association for Psychopharmacology consensus statement on evidence-based treatment of insomnia, parasomnias and circadian rhythm disorders. Journal of Psychopharmacology, 24(11), 1577-1600. https://doi.org/10.1177/ 0269881110379307 